\title{
PSYCHOLOGICAL WELL-BEING OF ATHLETES WITH DISABILITY
}

\author{
Wiwien Dinar Pratisti, Hasanan Faruqi
}

Faculty of Psychology, Universitas Muhammadiyah Surakarta

\begin{abstract}
Background: Psychological well-being is fundamentally related to the way in which individuals negotiate their way through life challenges. People with disabilities are the most marginalized groups in the world that can experience bad psychological well-being. Disability is an impairment in cognitive, developmental, intellectual, mental, physical, sensory, or some combination of these. This study aimed to describe the psychological well-being of athletes with disability.

Subjects and Method: This was a qualitative study. A total of 5 athletes of the National Paralympic Committee was selected for this study. The theme of this study was psychological well-being among athletes with disability. The data were obtained from semi-structured psychological well-being interview using content analysis. The psychological well-being interview was a development of six-factor model of by Carol Ryff, consisting of positive relationships with others, personal mastery, autonomy, a feeling of purpose and meaning in life, and personal growth and development.

Results: A total of 4 of 5 athletes of the National Paralympic Committee stated that they were less psychologically well-being, and only 1 athlete stated psychologically well-being. There was 1 athlete who stated that he could not accept his condition, 2 athletes were classified as underdeveloped autonomy and lacked life goals, and 1 athlete was classified as underdeveloped in his personal growth.

Conclusion: Disability affects psychological well-being among the athletes of the National Paralympic Committee.
\end{abstract}

Keywords: disability, psychological well-being, athletes

Correspondence:

Wiwien Dinar Pratisti. Faculty of Psychology, Universitas Muhammadiyah Surakarta, Central Java. Email: wdp206@ums.ac.id. Mobile: 0818278956.

The $5^{\text {th }}$ International Conference on Public Health Best Western Premier Hotel, Solo, Indonesia, February 13-14, 2019 | 173 https://doi.org/10.26911/theicph.2019.02.18 